See discussions, stats, and author profiles for this publication at: https://www.researchgate.net/publication/318760262

\title{
After the event: Debrief to make a difference
}

Article · July 2017

\section{CITATIONS}

4 authors, including:

Diana M Austin

Auckland University of Technology

9 PUBLICATIONS 44 CITATIONS

SEE PROFILE
READS

243

Lesley Ferkins

Auckland University of Technology 12 PUBLICATIONS 74 CITATIONS

SEE PROFILE

Some of the authors of this publication are also working on these related projects:

Facillitating health professional wellbeing following critical incidents View project 


\section{After the event: debrief to make a difference}

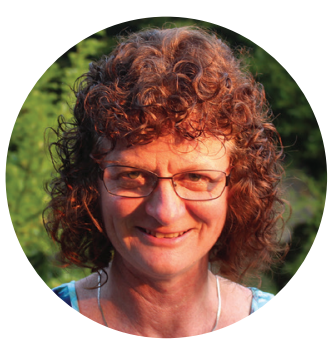

\section{Diana Austin \\ Midwifery Lecturer \& Programme Leader AUT, Doctoral candidate}

\section{A/Prof Lesley Ferkins Dr Jennie Swann Prof Liz Smythe}

An emergency code is called, you work together effectively as a team, the woman is stable, the family well informed, but what are you now thinking and feeling? There does not need to be a poor outcome in practice for us to question the care provided, relive the events and worry about what could have happened or what our team think of us. It is most likely that we will keep all these thoughts to ourselves as we perceive others are moving on, remaining emotionally strong to care for the next woman. We may have decided we are more sensitive than others in our team or that it is our own competence that is in question. This article will outline the common responses after a critical incident, such as a code event, and what has been found to be helpful for us and our colleagues. The information is informed by international literature and an action research study undertaken with health professionals at National Women's Health in Auckland from 2014-16.

\section{Common responses to critical incidents}

Within women's health there is a wide range of events that can be considered critical or traumatic; responding to an emergency code is one of them. Some are perceived to be more stressful than others depending on a multitude of factors, such as connection with the woman, what has gone on before, the health professional's role and the outcome. A relatively minor event can have an unexpected impact. Common emotions include shock, despair, anxiety, guilt, shame and fear. ${ }^{1,2} \mathrm{~A}$ study of 365 obstetricians in the USA found 53.7 per cent experienced a high level of grief following a stillbirth and other responses included selfdoubt, depression and self-blame. ${ }^{3}$ Critical events will continue to occur; as compassionate health professionals the impact will always be significant at some point in our career. This study explored what could make a difference for health professionals after being involved in a critical incident at National Women's Health, Auckland. Fifty health professionals worked collaboratively to develop and evaluate a support package that could facilitate wellbeing following a critical incident. The result was an understanding of what can work in practice and the creation of a Critical Incident eBook available on the National Women's Health and Health Quality and Safety Commission websites.

\section{Gathering together - to debrief or not}

Debriefing is often the focus of organisations when looking for support strategies. The reality in healthcare is that debriefings are frequently difficult to organise. In the 21st century, we have the opportunity to be more creative in the way we provide what is helpful after critical incidents using technology to create virtual gatherings, online discussions and resources. There are a variety of activities currently referred to as debriefing. The literature is unclear on the benefits of psychological debriefing and the authors of a Cochrane Systematic review caution about mandating its use. ${ }^{4}$ As a form of learning and team building, studies are indicating that structured debriefings can have an impact on patient safety. 5,6 This study found that it is not the debriefing that should be the focus, but rather it is the characteristics and qualities demonstrated in interactions that are powerful in assisting health professionals. Important qualities of all interactions after critical incidents, including debriefing, will be discussed in the next sections.

\section{Be open about the impact of critical incidents}

Role modelling of openness about unexpected outcomes and how they make us feel is needed to change the expectation that emotions remain hidden. Interviews with health professionals at National Women's Health uncovered silence around the impact of critical incidents. Members of all professional groups were found to presume they were the only ones experiencing stressful reactions, a finding similar to other studies. ${ }^{1}$ This belief led to a generalised behaviour of keeping feelings and thoughts hidden at work, expressing them only in private or with trusted family/friends. The organisation of a debriefing was validating for the participants in the study as it made them aware that others were also impacted. Senior health professionals were found to require as much support as more junior members with one stating, 'I try to look after my team, but who looks after me?'

\section{Learning environments without judgement}

Individual blame has little contribution to improving safety when working in a complex organisation where our intent is to provide the best care possible. A requirement to heal after a critical incident is to clearly understand what happened, why and what could have been done differently. A well-organised debrief can achieve this. Most people, given the right environment to gather the facts and reflect, are able to identify their own areas for improvement going forward. In conversations with colleagues one needs to avoid the blaming discourse, such as 'Did you do this?' or 'Why did you...?' but instead offering 'Tell us what happened'. In a group meeting or one-to-one 
discussions, take notes of ideas for change and make them a reality.

\section{Provide professional reassurance}

Providing reassurance that colleagues remain valued team members is essential. It is not to dismiss conversations of accountability for actions, but rather acknowledges the self-doubt that poor or unexpected outcomes can bring. After a significant event there can be the internal dialogue that begins to question our competence to keep practising. A common concern after a critical incident is reflected by this participant's statement that they 'would worry about being incompetent and having missed something.' There is also concern about what colleagues think. Feelings of shame can immobilise us to seek help, from each other or formally.

\section{Facilitate time out}

Taking time away from the workplace may be part of moving forward, a need that is often recognised by others before the individual concerned. Many safety analogies are taken from the airline industry. However, when it comes to continuing to practice after a traumatic event in health, unlike the airline industry, it is expected that health professionals move on to the next woman without hesitation. Although often impractical, there are many senior health professionals who can remember a time in their career when space was needed, space that created resilience in the long term. As one participant in the study stated, 'I had a couple of weeks off work, which l'd never done before or since.' Having space, however, may be just a coffee in a quiet room or having a colleague listen at the end of the day. During a debriefing, acknowledge and offer what is most needed.

\section{Access information going forward}

The absence of information about what happens next creates unnecessary fear and unhelpful assumptions. A debrief can be a time for team members to gather information on what will happen next. Will there be an internal investigation? If so, what sort and what will it involve? Knowing the policy requirements of an organisation and triggers for a review can remove the perception that it is being undertaken to establish blame. Health professionals involved in a review should be facilitated to provide their account of both the story of what happened and the analysis of how (or if) care could have been different. Information for ongoing support should also be made available, such as via Employment Assistant Programs, in a way that is not linked to weakness but to ongoing wellness.

\section{Conclusion}

Most health professionals keep quiet about the effects of critical incidents and this creates an environment where common needs remain hidden. This behaviour is adopted by new practitioners, perpetuating what appears to be an unsupportive environment. Whether it is a formal debriefing or a casual encounter with colleagues, we need to acknowledge the effect of what has happened to each other and create safe places to learn and change practice. In complex, busy health organisations, innovative ways may be required to gather groups together. However, facilitating positive support is possible in all interactions.

Further reading

The Critical Incident eBook can be accessed via http:// nationalwomenshealth.adhb.govt.nz/health-professionals/criticalincident-e-book.

\section{References}

1. Ullström S, Andreen Sachs M, Hansson J, et al. Suffering in silence: A qualitative study of second victims of adverse events. BMJ Quality \& Safety. 2014;23(4):325.

2. Sheen K, Spiby H, Slade P. The experience and impact of traumatic perinatal event experiences in midwives: A qualitative investigation. International Journal of Nursing Studies. 2016;53:61-72

3. Farrow VA, Schulkin J, Goldenberg RL, Fretts R. Psychological impact of stillbirths on obstetricians. Journal of Maternal-Fetal and Neonatal Medicine. 2013;26(8):748-52

4. Rose S, Bisson J, Churchill R, Wessely S. Psychological debriefing for preventing post traumatic stress disorder (PTSD). Cochrane of Systematic Reviews. 2009

5. Corbett N, Hurko P, Vallee JT. Debriefing as a strategic tool for performance improvement. Journal of Obstetric, Gynecologic, \& Neonatal Nursing. 2012;41(4):572-9.

6. Weinschreider J, Dadiz R, editors. Coming to the table Debriefing for patient safety. AWHONN Annual Convention, 2010

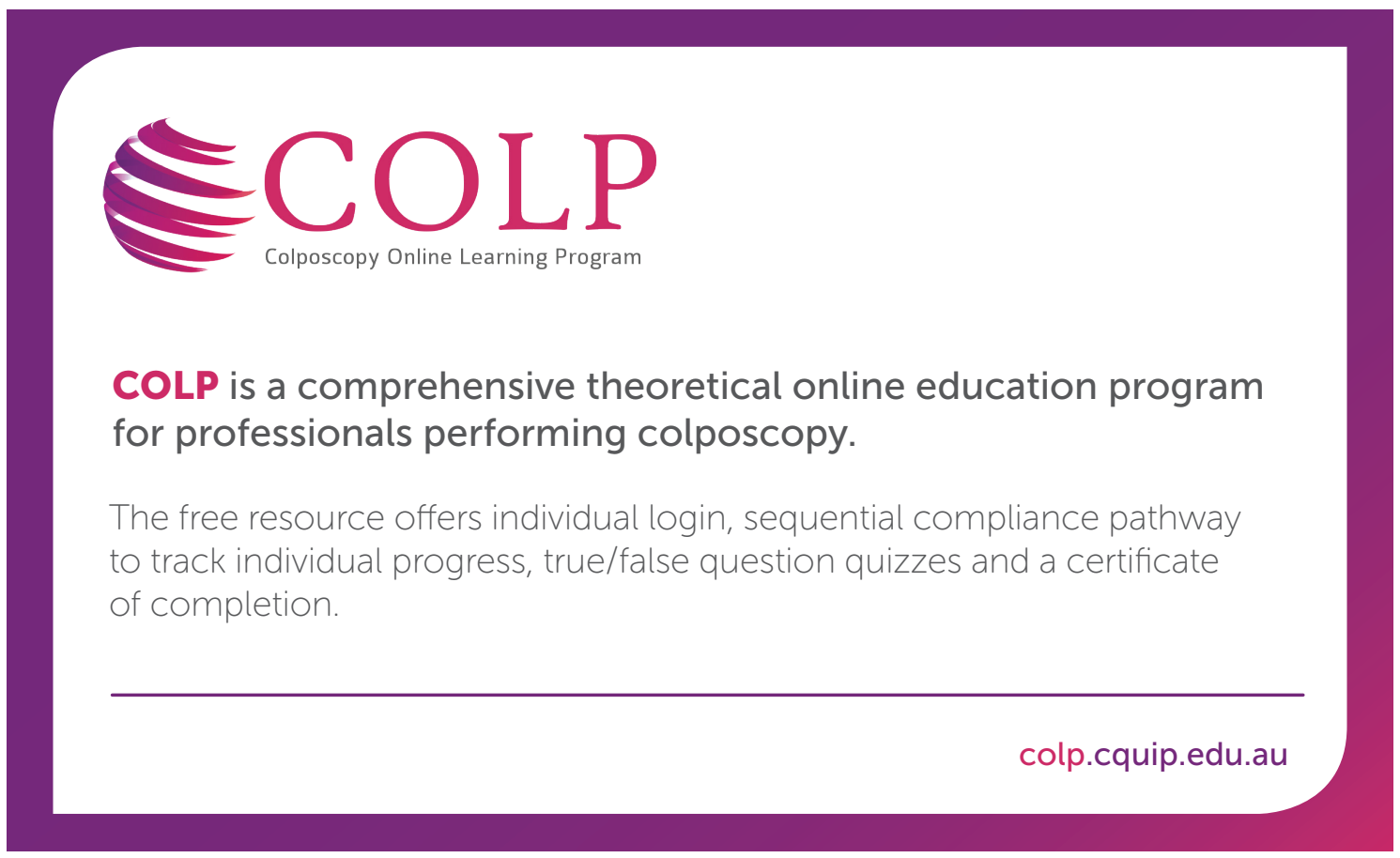

